\title{
Assessing the Influence of Roasting Process Parameters on Mepiquat and Chlormequat Formation in Dark Barley Malts
}

\author{
Adam Ekielski $^{1}$ (D) $\cdot$ Pawan Kumar Mishra ${ }^{2} \cdot$ Tomasz Żelaziński $^{1}$ \\ Received: 31 January 2017 / Accepted: 21 February 2018 / Published online: 14 March 2018 \\ (C) The Author(s) 2018
}

\begin{abstract}
The aim of this work was to examine the effect of temperature and time on mepiquat and chlormequat pesticides' formation during the barley malt roasting process. The study was conducted for roasting of green malt and kilned malt. The barley used for the study was of the ecological type and verified by us to be free of any quaternary ammonium pesticides. In our study, we observed the formation of chloromequat (CHLM) along with mepiquat (MPQ). Both the compounds share the similarity in quaternary ammonium structure but to the best of our knowledge, it is the first report where CHLM formation has been observed during the roasting process. Additionally, we tried to study the effect of processing parameters (temperature and time) on the quantity of MPQ and CHLM formed during the process, using response surface methods. Additionally, the effect of process parameters (time and temperature) on the color parameter of luminosity $\left(\mathrm{L}^{*}\right)$ values was also studied using the response surface methodology. The key factor which determined the amount of compounds produced in the course of roasting was found to be temperature; on the other hand, duration of roasting was observed to be of lesser effect. In the process of roasting dry malt, the CHLM presence was detected at a temperature above $433 \mathrm{~K}\left(160{ }^{\circ} \mathrm{C}\right)$, while the MPQ content was found to be present at a temperature above $442 \mathrm{~K}\left(169^{\circ} \mathrm{C}\right)$. In the case of green malt, the temperature at CHLM and MPQ content was detected and was found to be higher than kilned malt. We also observed that CHLM formed at lower temperatures and shorter roasting time as compared to MPQ.
\end{abstract}

Keywords Pesticides $\cdot$ Eco barley $\cdot$ Green malt $\cdot$ Bio beer

\section{Introduction}

Chlormequat (CHLM) and mepiquat (MPQ) are common quaternary ammonium pesticides used as plant growth regulators. Their ill-effects in humans and animals have been widely reported and studied (Jones et al. 2013; Nisse et al. 2015; Xiagedeer et al. 2016); hence, the permissible CHLM and MPQ content level in a unit of mass of a barley is 3 and $4 \mathrm{mg} / \mathrm{kg}$, respectively (EFSA 2008; Jones et al. 2013). Some researchers suggest that CHLM introduced into a human body even below this level would affect human reproductive

Adam Ekielski

adam_ekielski@sggw.pl

1 Faculty of Production Engineering, Faculty of Production Engineering, Warsaw University of Life Sciences, Warsaw, Poland

2 Department of Wood Processing Technology, Faculty of Forestry and Wood Technology, Mendel University in Brno, Brno, Czech Republic systems (Torner et al. 1999). Some studies indirectly infer that exposed rats with a low dose of CHLM show an effect on their metabolism (Bonvallot et al. 2014).

Recent works established MPQ as a byproduct of the roasting process of coffee and barley grains and also correlated its presence with a change in color during roasting (Bessaire et al. 2016; Hammel et al. 2014; Wermann et al. 2014). Maillard reaction drove the MPQ formation through to the degradation of lysine (amino acid) in the presence of trigonelline (alkaloid), conjugated with a temperature of typical roasting conditions (Hammel et al. 2014). In addition to MPQ, melanoidins have also been reported to be formed by Maillard-like reactions during the roasting process of Barley and coffee (Bekedam et al. 2008; Moreira et al. 2012; Papetti et al. 2006). These melanoidins are also responsible for color changes during the roasting process (Papetti et al. 2006). Therefore, a close connection between product color changes and MPQ formation can be assumed. From these facts, we can also infer that higher roasting temperature generated higher MPQ content in roasted products as the consequence of nonenzymatic browning reaction. But during analysis of MPQ 
contents in other different cereal products, treated in typical oven conditions, it was found that the MPQ was not formed (Wermann et al. 2014). The conclusion of these observations was that MPQ formation during drying and baking conditions was correlated with baking or roasting temperature but at a temperature below $155{ }^{\circ} \mathrm{C}$ MPQ was not formed. A further literature search showed that statistical probability formation of the MPQ compounds in cereals during thermal treatment below $200^{\circ} \mathrm{C}$ is extremely low. The MPQ formation process starts at the temperature above $200{ }^{\circ} \mathrm{C}$ in cereals containing free lysine (Bessaire et al. 2016). Bessaire et al. (2016) showed that levels of MPQ are not correlated with a* (CieLab color space) color parameter and well correlated with $\mathrm{L}^{*}\left(r^{2}=0.62\right)$ and $\mathrm{b} *\left(r^{2}=0.76\right)$ parameters.

Brewing process itself has been in focus for the presence of pesticides in beer (Bessaire et al. 2016). Brewery malt is one of the basic ingredients necessary for beer production. Dark

\section{a}

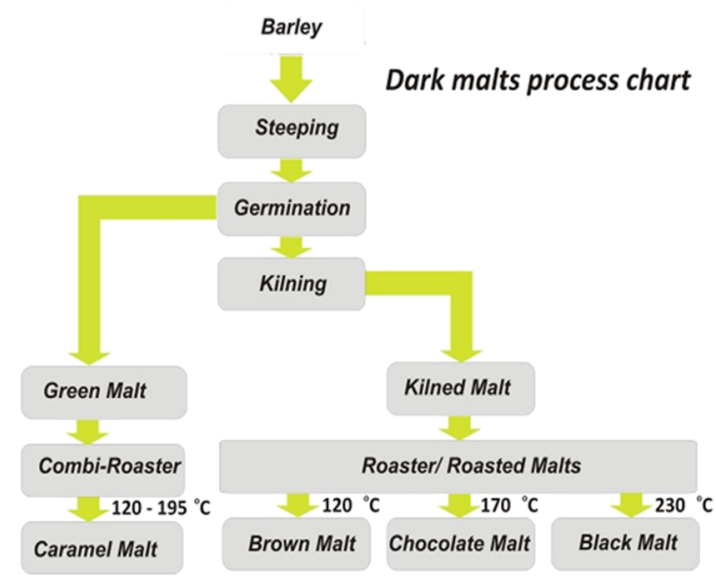

C
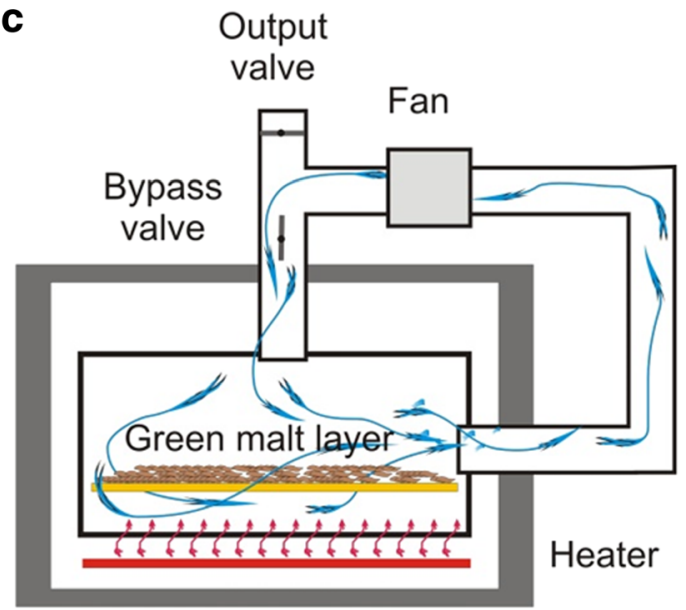

stage 1

malt types are derived by heating malt at the temperatures exceeding $80^{\circ} \mathrm{C}$, generally. In the case of production of special dark malts, the roasting temperature between 160 and $240{ }^{\circ} \mathrm{C}$ (Kim et al. 1993) is also used. Two technologies in the production of dark malt can be recognized (Fig. 1a). The first consists of roasting the green malt and with this technology caramel malt is produced. Caramel malts are produced in roasters at temperatures that cause saccharification of green malt (germinated barley) with an initial moisture content of $42-45 \%$ (Gruber 2001). The green malt is then moved directly into the roasting drum (Fig. 1c). The second technology involves roasting of dry malt (after kilning) and giving brown, chocolate, and black malts (Fig. 1c). Black malt is produced from dry malt by heating up to 150 to $240{ }^{\circ} \mathrm{C}$ for 50 to $90 \mathrm{~min}$. Due to safety reasons in industrial conditions, the final phase involves the injection of a small amount of water. The caramel malt (crystal malt) is produced in a different way; it begins

b

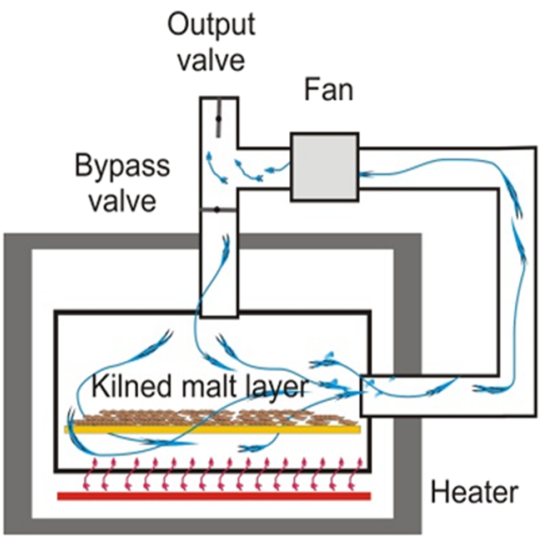

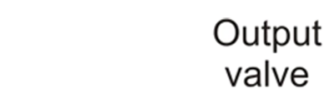

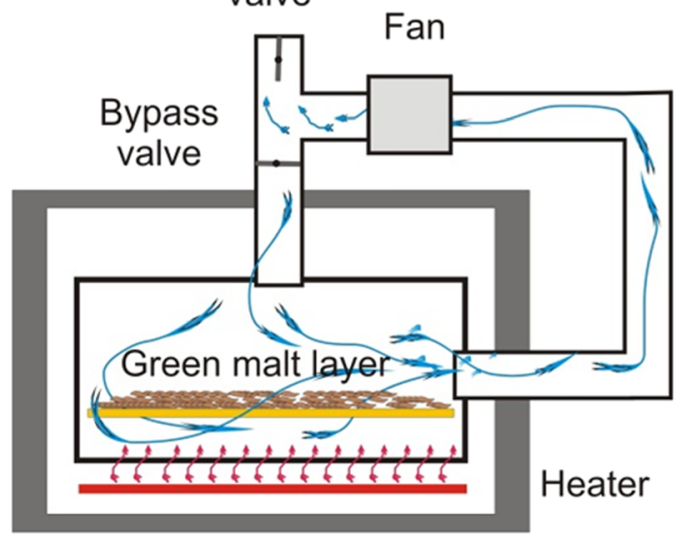

stage 2

Fig. 1 Dark malt process chart (a), experimental roasted malt production chamber used during experiment (b), two-stage experimental caramel malt production chamber used during experiment (c) 

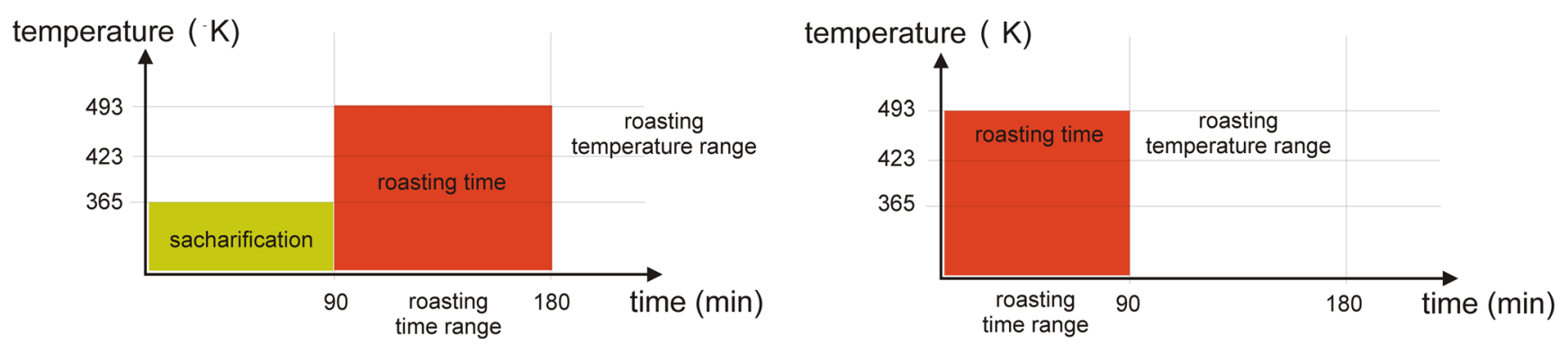

Fig. 2 Temperature and time profile during caramel (left) and roasted dry/kilned (right) malts production process

with the introduction of wet green malt to a sealed drum roaster (above of $38 \%$ moisture contents). The product is a long "stewed" at $65^{\circ} \mathrm{C}$ for 50-90 min, during which time the drum is sealed to maintain a moist environment. Such conditions are conducive to an extent for the activity of enzymes within the malt. In a particular case, the formation of flavor happens by a prolongation of the enzymes action, which acts by degrading the starch to dextrin and simple sugars. This action increases the concentration of the precursors of the Maillard reaction. After a period of stewing, the window to outlet chamber of the roaster is opened and thereby allowing the gases and steam to pass through the malt causing it to dry and roast. The product is roasted at a temperature of 150 to $200{ }^{\circ} \mathrm{C}$ for $90-100 \mathrm{~min}$. The main difference between two types of processing is at first stage, in which product is treating at a relatively high humidity during the initial phase of roasting. Many brewers have also introduced ecological beers to the market. A condition for a beer to be recognized as an ecological beer is the absence of any compound, which is not of natural origin. The processed barley and malt derived from it should not contain any MPQ and CHLM compounds at the limit of detection.

In this study, we report the formation of CHLM along with MPQ during the malt roasting process (for green and kilned malts) and tried it to find the optimal condition of processing parameters for the quantity of pesticide formed using response surface methodology. Impact of process parameters (time and temperature) on the color lightness parameter $\left(\mathrm{L}^{*}\right)$ values were also studied using response surface methods.

\section{Materials and Methods}

\section{Sample Preparation}

Two groups of malt samples were obtained directly from malt house factory. The tests were carried out by roasting green and dry malt derived from ecological barley. The same ecological barley was used to produce green and dry malt. To recognize and trace malt production, every barley batch was signed of its own batch number. During malt production process, the malt house staff used this batch number to sample identification. Before experimenting the barley, green and dried (kilned) malt was tested for lack of pesticide contamination using the methods reported in "Chemical Analysis of MPQ and CHLM in Examined Samples." The initial green malt moisture was $42 \pm 1 \% \mathrm{w} /$ $w$ and dry malt contained $7 \% w / w$ water. For the roasting process, the malt samples of weight $(1000 \mathrm{~g})$ were used. The experiments were conducted for green malt and dry malt separately with three replications of each. The test sample was placed in the steam oven used as a roaster. For the uniformity of the heat supply, the malt layer did not exceed
Table 1 Experimental design DOE, $3 * *(2-0)$, with process variables (coded and uncoded) and experimental results of kilned malt roasted

\begin{tabular}{|c|c|c|c|c|c|c|c|c|}
\hline \multirow[t]{2}{*}{ Trail code } & \multirow[t]{2}{*}{ Block } & \multicolumn{2}{|c|}{ Roasting temperature $\mathrm{T}(\mathrm{K})$} & \multicolumn{2}{|c|}{ Roasting time $\mathrm{t}(\mathrm{min})$} & \multirow{2}{*}{$\begin{array}{l}\text { MPQ } \\
(\mathrm{mg} / \mathrm{kg})\end{array}$} & \multirow{2}{*}{$\begin{array}{l}\text { CHLM } \\
(\mathrm{mg} / \mathrm{kg})\end{array}$} & \multirow{2}{*}{$\begin{array}{l}\mathrm{L}^{*} \\
(-)\end{array}$} \\
\hline & & Coded & Uncoded & Coded & Uncoded & & & \\
\hline 6 & 2 & 0 & 458 & -1 & 10 & $0 *$ & 0.040 & 27.71 \\
\hline 3 & 1 & -1 & 423 & -1 & 10 & $0^{*}$ & $0^{*}$ & 74.32 \\
\hline 9 & 3 & 0 & 458 & 0 & 50 & 0.014 & 0.044 & 18.52 \\
\hline 2 & 1 & 1 & 493 & 0 & 50 & 0.42 & 0.051 & 1.20 \\
\hline 5 & 2 & 1 & 493 & 1 & 90 & 0.44 & 0.058 & 1.18 \\
\hline 7 & 3 & 1 & 493 & -1 & 10 & 0.34 & 0.043 & 5.24 \\
\hline 4 & 2 & -1 & 423 & 0 & 50 & $0 *$ & 0.006 & 33.29 \\
\hline 8 & 3 & -1 & 423 & 1 & 90 & 0.009 & 0.009 & 33.13 \\
\hline 1 & 1 & 0 & 458 & 1 & 90 & 0.089 & 0.051 & 8.96 \\
\hline
\end{tabular}

*Results below method sensitivity $(0.005 \mathrm{mg} / \mathrm{kg})$ 
Table 2 Experimental design DOE, $3 * *(2-0)$, with process variables (coded and uncoded) and experimental results of green malt roasted

\begin{tabular}{|c|c|c|c|c|c|c|c|c|}
\hline \multirow[t]{2}{*}{ Trail code } & \multirow[b]{2}{*}{ Block } & \multicolumn{2}{|c|}{ Roasting temperature $\mathrm{T}(\mathrm{K})$} & \multicolumn{2}{|c|}{ Roasting time $\mathrm{t}(\mathrm{min})$} & \multirow{2}{*}{$\begin{array}{l}\text { MPQ } \\
(\mathrm{mg} / \mathrm{kg})\end{array}$} & \multirow{2}{*}{$\begin{array}{l}\text { CHLM } \\
(\mathrm{mg} / \mathrm{kg})\end{array}$} & \multirow{2}{*}{$\begin{array}{l}\mathrm{L}^{*} \\
(-)\end{array}$} \\
\hline & & Coded & Uncoded & Coded & Uncoded & & & \\
\hline 6 & 2 & 0 & 458 & -1 & 10 & $-*$ & 0.008 & 27.71 \\
\hline 3 & 1 & -1 & 423 & -1 & 10 & $-*$ & $-*$ & 74.32 \\
\hline 9 & 3 & 0 & 458 & 0 & 50 & 0.012 & 0.009 & 18.52 \\
\hline 2 & 1 & 1 & 493 & 0 & 50 & 0.41 & 0.026 & 1.20 \\
\hline 5 & 2 & 1 & 493 & 1 & 90 & 0.42 & 0.034 & 1.18 \\
\hline 7 & 3 & 1 & 493 & -1 & 10 & 0.25 & 0.022 & 5.24 \\
\hline 4 & 2 & -1 & 423 & 0 & 50 & $-*$ & $-*$ & 33.29 \\
\hline 8 & 3 & -1 & 423 & 1 & 90 & -* & 0.009 & 33.13 \\
\hline 1 & 1 & 0 & 458 & 1 & 90 & 0.07 & 0.01 & 18.52 \\
\hline
\end{tabular}

*Below method sensitivity $(0.005 \mathrm{mg} / \mathrm{kg})$
5-6 $\mathrm{mm}$. It simulated the roasting process conditions of the industrial roasting drums.

Oven temperature range and humidity could be varied between 100 to $300{ }^{\circ} \mathrm{C}$ and 0 to $100 \%$ respectively. The roasting system used in the experiment was equipped with "close mode," allowing to carry out the process at a predetermined air humidity (Fig. 2a), or "open mode," wherein oven working as a roaster in dry conditions (Fig. 2b). The roaster control system was able to control the temperature and air humidity inside the roaster chamber with $3 \%$ accuracy. The temperature profile during the roasting for both types of malts can be found in Fig. 2. The green malt roasting contains two stages: before high-temperature roasting, the green malts were stored at $80{ }^{\circ} \mathrm{C}$ temperature for $90 \mathrm{~min}$, with $100 \%$ environmental humidity. In the next step, roasting at high temperature from 150 to $230^{\circ} \mathrm{C}$ was done. Roasting of dry malt was performed at high temperature only (Fig. 2).

\section{Chemical Analysis of MPQ and CHLM in Examined Samples}

The analysis of MPQ and CHLM content of unroasted and roasted samples was performed at Research Institute of Horticulture in Skierniewice, Department of Food Safety Research (Accredited laboratory in the Food Safety Research Department, http://www.pca.gov.pl), Poland. All experiments were done using an Agilent 1260 Series LC/MS system (details in Tables 9 and 10). Chlormequat chloride and mepiquat chloride were purchased from Sigma-Aldrich, while mepiquat iodide D3 and chlormequat D4 were obtained from Dr. Ehrenstorfer GmbH (Augsburg, Germany). Other reagents used were acetonitrile LC/MS grade (Merck), formic acid LC/ MS grade (Fluka), water LC/MS grade (Merck (Direct-Q)), methanol LC/MS grade (Merck), and ammonium formate (Fluka). The limit of quantification (LOQ) of MPQ and CHLM content was $0.005 \mathrm{mg} / \mathrm{kg}$. The accuracy of the measured values was determined at the $95 \%$ confidence level. Individual pesticides' stock solutions containing $1000 \mu \mathrm{g} /$ $\mathrm{mL}$ of the target analytes were prepared by dissolving $25 \mathrm{mg}$ reference standards in $25 \mathrm{~mL}$ of methanol and stored in a freezer $\left(\leq-20^{\circ} \mathrm{C}\right)$ and all dilutions were also stored in the refrigerator. Working stock standard mixture in methanol containing $10 \mu \mathrm{g} / \mathrm{ml}$ of each compound was prepared by mixing appropriate quantities of the individual stock solutions. For sample extraction, $5 \mathrm{~g}$ of the sample was weighed into a 50 -mL Teflon centrifuge tube and $10 \mathrm{~mL}$ of water was added to it. The tube was closed and shaken vigorously by a Vortextype shaker for $5 \mathrm{~min}$. To the same tube, $10 \mathrm{~mL}$ of methanol ( $+1 \%$ vol. formic acid) and $50 \mu \mathrm{L}$ of the internal standard solution were added; the tube was closed and shaken vigorously by a Vortex-type shaker for $30 \mathrm{~min}$. The sample was centrifuged using laboratory centrifuge for $5 \mathrm{~min}$ at $7200 \mathrm{rpm}$.

Table 3 Results of variance analysis of empirical model for MPQ content, determination, and corrected determination coefficients obtained during experiment of kilned malt: $r^{2}=0.82253$. SS sum of squares, $d f$ degree of freedom, $M S$ sum of mean squares, $F F$ statistics, $p$ value of test probability

\begin{tabular}{llcrr}
\hline Source of variation & SS & Df & MS & $F$ \\
\hline Time (t) & 0.051698 & 1 & 0.051698 & 6.82699 \\
Temperature (T) & 0.186963 & 1 & 0.186963 & 0.030993 \\
Interaction & 0.047556 & 1 & 0.047556 & 0.001095 \\
Pure error & 0.060580 & 8 & 0.007573 & 0.036598 \\
Total sum of squares & 0.341359 & 11 & & \\
\hline
\end{tabular}


Table 4 Results of variance analysis of empirical model for CHLM content, determination, and corrected determination coefficients obtained during experiment of kilned malt: $R^{2}=0.7125$ i $R_{\mathrm{p}}{ }^{2}=0.6047$. $S S$ sum of squares, $d f$ degree of freedom, $M S$ sum of mean squares, $F F$ statistics, $p$ value of test probability

\begin{tabular}{llcrrr}
\hline Source of variation & SS & Df & MS & $F$ & $P$ \\
\hline Time (t) & 0.001988 & 1 & 0.001988 & 12.41666 \\
Temperature (T) & 0.001018 & 1 & 0.001018 & 6.35965 & 1.50655 \\
Interaction & 0.000241 & 1 & 0.000241 & 0.0007803 \\
Pure error & 0.001281 & 8 & & 0.035707 \\
Total sum of squares & 0.004456 & 11 & & \\
\hline
\end{tabular}

An aliquot of $0.5 \mathrm{~mL}$ of the extract was transferred to a new Eppendorf safe-lock tube and subsequently diluted with 0 . $4 \mathrm{~mL}$ of methanol (+1\% vol. formic acid) and $100 \mu \mathrm{L}$ methanol. The content was vortexed gently and filtered through the $0.22-\mu \mathrm{m}$ Teflon filter attached to a syringe directly into amber HPLC vial. Final determination was performed using LC-MS/ MS.

For chromatographic and mass spectrometry conditions, please refer to Tables 9 and 10 .

\section{Measurement of Color Space Parameter ( $\left.L^{*}\right)$}

All samples for color space parameters measurement were milled (Bosch MKM 6000 impact mill) and subsequently sieved (sieve size \# 0.05,0,01, 0.15, 0.25, $0.5 \mathrm{~mm}$, DIN ISO 3310 -1, vibration amplitude $6 \mathrm{~mm}$, and vibration frequency $2.0 \mathrm{~Hz}$ ) for $10 \mathrm{~min}$ to obtain an average particle size of $100 \mu \mathrm{m}$. Color space parameters were measured using the CIE L*a*b* (CIELAB) color description system of the CIECommission Internationale de l'Eclairage (International Commission on Illumination) which is one of the most often used standards for color evaluation (Bessaire et al. 2016; Lee et al. 2013; Ohta and Robertson 2005). The advantage of this method lies in the fact that it utilizes three independent coordinate axes viz. color luminosity ( $\left.\mathrm{L}^{*}\right), \mathrm{a}^{*}$-(redness-greenness) and $\mathrm{b} *$-(yellowness-blueness) (Ohta and Robertson 2005).

All measurements were done using a self-fabricated instrument assembly $(80 \times 40 \times 40 \mathrm{~cm}$, with inside matte black walls, illuminated with 15 fluorescent lights TL-D De Luxe Pro (Philips), with a color temperature $6500 \mathrm{~K}$ ). The colorimeter has undergone the validation process by using the Minolta calibration plate and is approved for this use. The samples were spread on black paper and then photographed in a light chamber equipped with D65 fluorescent lamps using the CCD color camera ac A2500-14uc (5 Mpx, Basler, Ahrensburg, Germany). The visual analysis was done using NI Visio Assistance software, produced by National Instruments. In our research, color changes' parameter ( $\mathrm{L}^{*}$ ) was used in the range from 0 (pure black) to 100 (pure white).

\section{Response Surface Analysis}

In setting up the research plan, the DOE (design of experiment) central composite plan was used. These techniques when applied to experiment design help to reduce the number of trials and save time. The DOE plan is adopted in our experiment to estimate response surface and further to optimize the process parameters in the roaster. In the formation of the central plan, the roasting temperature (RT) limit values of $\mathrm{T} 1=423 \mathrm{~K}\left(150{ }^{\circ} \mathrm{C}\right)$ and $\mathrm{T} 2=493 \mathrm{~K}\left(230^{\circ} \mathrm{C}\right)$ and the roasting time lower time limit $\mathrm{t} 1=10 \mathrm{~min}$ and an upper limit of $\mathrm{t} 2=90$ min were adopted. The DOE experiment plan $3 * *(2-0)$ was used; the generated coded data have been presented in Tables 1 and 2.

The generation of response surface plots and statistical analysis was carried out using DOE module in statistical software (Statistica v.2016, StatSoft, USA).

The coded and real values of the independent process variables with design matrix are given in Tables 1 and 2. The

Table 5 Results of variance analysis of empirical model for color parameter $\left(\mathrm{L}^{*}\right)$, determination, and corrected determination coefficients obtained during experiment of kilned malt: $r^{2}=0.74542$. $S S$ sum of squares, $d f$ degree of freedom, $M S$ sum of mean squares, $F F$ statistics, $p$ value of test probability

\begin{tabular}{|c|c|c|c|c|c|}
\hline Source of variation & SS & Df & MS & $F$ & $P$ \\
\hline Time $(\mathrm{t})$ & $17.176,34$ & 1 & $17.176,34$ & 20.83619 & 0.001839 \\
\hline Temperature (T) & 2131.56 & 1 & 2131.56 & 2.58574 & 0.064497 \\
\hline Interaction & 80.46 & 1 & 80.46 & 0.09760 & 0.076271 \\
\hline Pure error & 6594.81 & 8 & 824.35 & & \\
\hline Total square error & $25.904,59$ & 11 & & & \\
\hline
\end{tabular}


Table 6 Results of variance analysis of empirical model for MPQ content, determination, and corrected determination coefficients obtained during experiment of green malt: $r^{2}=0.80615$. SS sum of squares, $d f$ degree of freedom, $M S$ sum of mean squares, $F F$ statistics, $p$ value of test probability

\begin{tabular}{|c|c|c|c|c|c|}
\hline Source of variation & SS & Df & MS & $F$ & $P$ \\
\hline Time (t) & 0.0096 & 1 & 0.0096 & 0.945033 & 0.375634 \\
\hline Temperature $(\mathrm{T})$ & 0.1944 & 1 & 0.1944 & 19.13691 & 0.007191 \\
\hline Interaction & 0.007225 & 1 & 0.007225 & 0.711236 & 0.437508 \\
\hline Pure error & 0.050792 & 5 & 0.010158 & & \\
\hline Total sum of squares & 0.262017 & 8 & & & \\
\hline
\end{tabular}

Table 7 Results of variance analysis of empirical model for chlormequat content (CHLM), determination, and corrected determination coefficients obtained during experiment of green malt: $r^{2}=0.89377$. SS sum of squares, $d f$ degree of freedom, $M S$ sum of mean squares, $F F$ statistics, $p$ value of test probability

\begin{tabular}{|c|c|c|c|c|c|}
\hline Source of variation & SS & df & MS & $F$ & $P$ \\
\hline Time $(\mathrm{t})$ & 0.000088 & 1 & 0.000088 & 3.790303 & 0.109107 \\
\hline Temperature (T) & 0.000888 & 1 & 0.000888 & 38.18246 & 0.001618 \\
\hline Interaction & 0.000002 & 1 & 0.000002 & 0.096728 & 0.768340 \\
\hline Pure error & 0.000116 & 5 & 0.000023 & & \\
\hline Total sum of squares & 0.001094 & 8 & & & \\
\hline
\end{tabular}

levels of each independent variable were found according to declared ranges of process parameters.

\section{Results and Discussion}

MPQ and CHLM both belong to the quaternary ammonium compound category. For the MPQ formation during roasting processes, two different routes have been proposed in literature. First, in the presence of free lysine, reducing sugar and alkylating agent, a maillard-like reaction leads to the formation of MPQ (Bessaire et al. 2016; Hammel et al. 2014; Wermann et al. 2014). The second route includes the temperature-assisted direct decarboxylation of pipecolic acid and pipecolic acid betaine leading to direct formation of MPQ and piperidine. Piperidine is later converted to MPQ with the help of a methylating agent (Yuan et al. 2017a, b). The color change during the roasting process (coffee and barley) has also been studied and explained by the formation of melanoidins. The melanoidins are final products of Maillard reaction along with a complex mix of various compounds of different molecular weights and advanced glycation endproducts (AGEs). These chromophores (alone and conjugated) are responsible for the coloration of roasted products. They absorb light at wavelengths as high as $420 \mathrm{~nm}$ and are predominantly responsible for the characteristic brown color of roasted food products (Wang et al. 2011). Melanoidins were also reported to be formed by Maillard-like reaction, leading to the color change (Bekedam et al. 2008; Moreira et al. 2012; Papetti et al. 2006). L* color parameter of roasted products has already been correlated with the quantity of acrylamide and MPQ and results have already been reported, where these products were proposed to be formed via Maillard reaction (Bessaire et al. 2016; Mizukami et al. 2016, 2014).

Table 8 Results of variance analysis of empirical model for color lightness parameter ( $\mathrm{L}^{*}$ ), determination, and corrected determination coefficients obtained during experiment of green malt: $r^{2}=0.90453$. $S S$ sum of squares, $d f$ degree of freedom, $M S$ sum of mean squares, $F F$ statistics, $p$ value of test probability

\begin{tabular}{lllll}
\hline Source of variation & SS & Df & MS & $F$ \\
\hline Time (t) & 539.032817 & 1 & 539.032817 & 6.490359 \\
Temperature (T) & 2969.93002 & 1 & 2969.93002 & 35.760183 \\
Interaction & 425.390625 & 1 & 425.390625 & 5.122022 \\
Pure error & 415.256542 & 5 & 83.051308 & 0.051415 \\
Total square error & 4349.61 & 8 & & \\
\hline
\end{tabular}



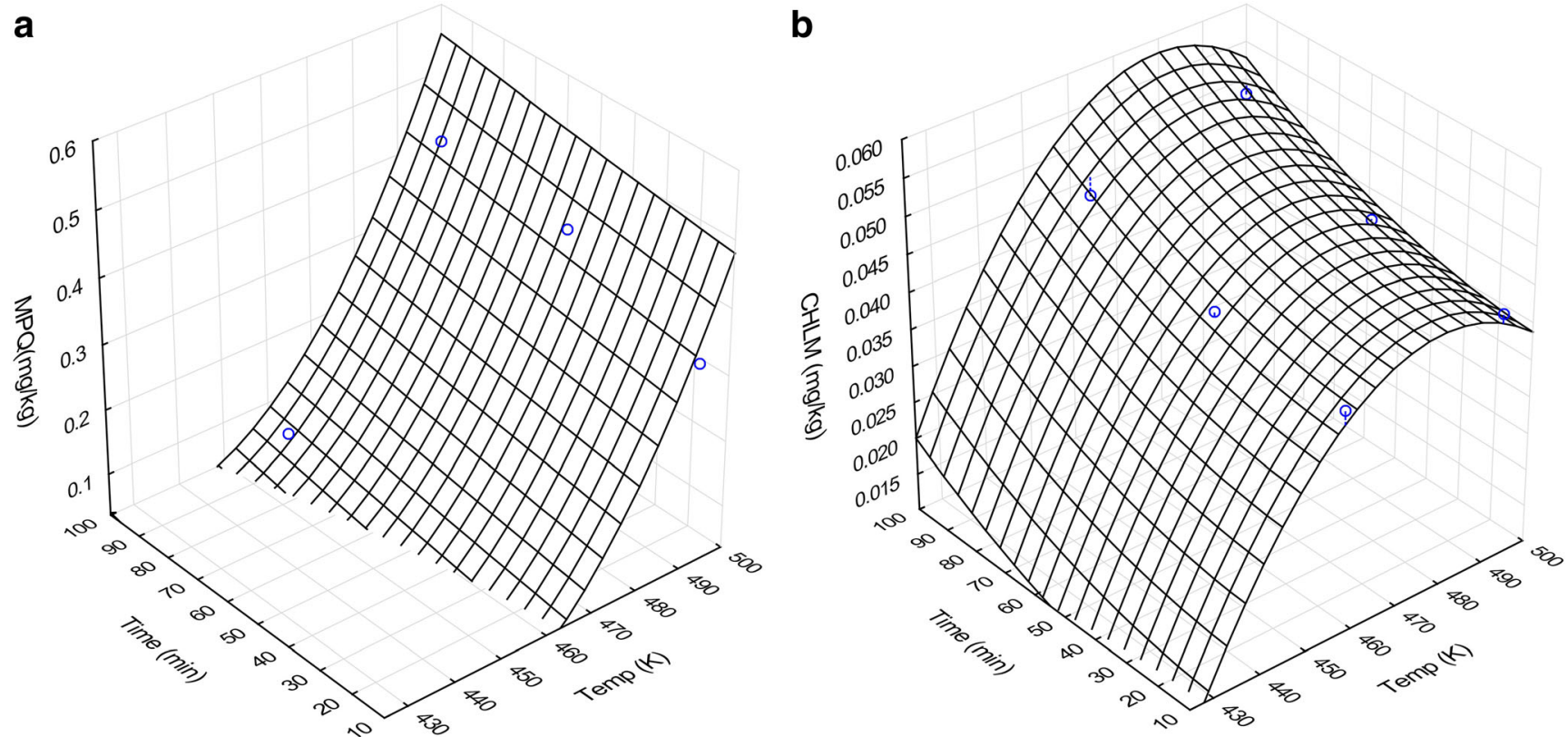

Fig. 3 Response surface diagrams illustrating the effect of temperature and process time on mepiquat (a) and chlormequat (b) contents during roasting the kilned malt

However, in this study, we observed the formation of CHLM along with MPQ. The effect of process parameters has been tried to study for change in $\mathrm{L}^{*}$ color parameter. Having said that, though we have tried to understand the effect of process parameters on browning, considering a number of possible chromophore byproducts from Maillard like reaction, it is difficult to conclude anything about quantity of pesticides formed and color parameter $\left(\mathrm{L}^{*}\right)$. The mechanism of formation of CHLM in the barley roasting process is not the target of this study, but along with Maillard-like reaction or thermalassisted direct decarboxylation-like reaction can be hypothesized to be responsible for the CHLM formation. Considering the structural similarity of choline, betaine, and trigonelline with the CHLM, which is in addition to the quaternary amine nature of these compounds, the possibility of Maillard-like reaction to be involved is likely, which is, in addition, the fact that choline, betaine, and trigonelline are commonly found in barley (Corol et al. 2012). The moisture content plays a key a

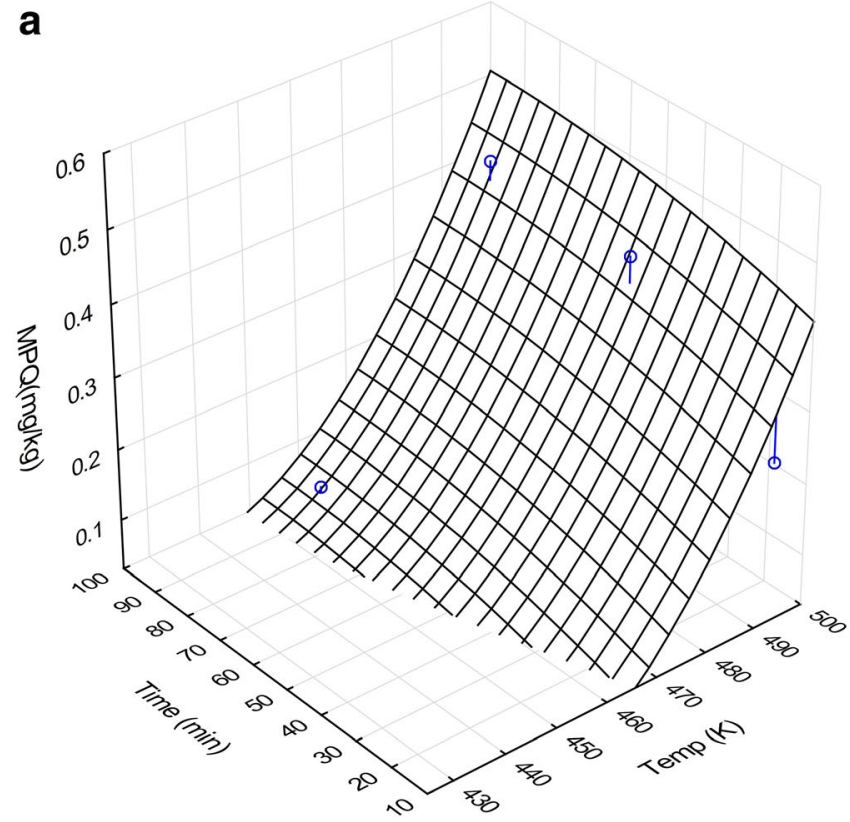

b

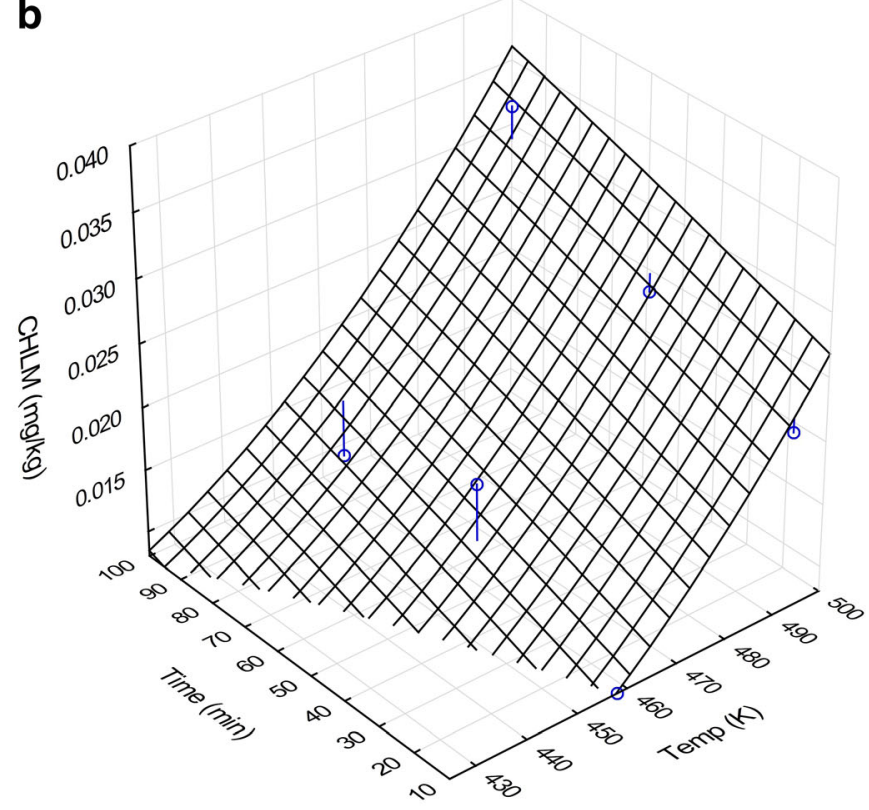

Fig. 4 Response surface diagrams illustrating the effect of temperature and process time on MPQ (a) and CHLM (b), contents during roasting the green malt 

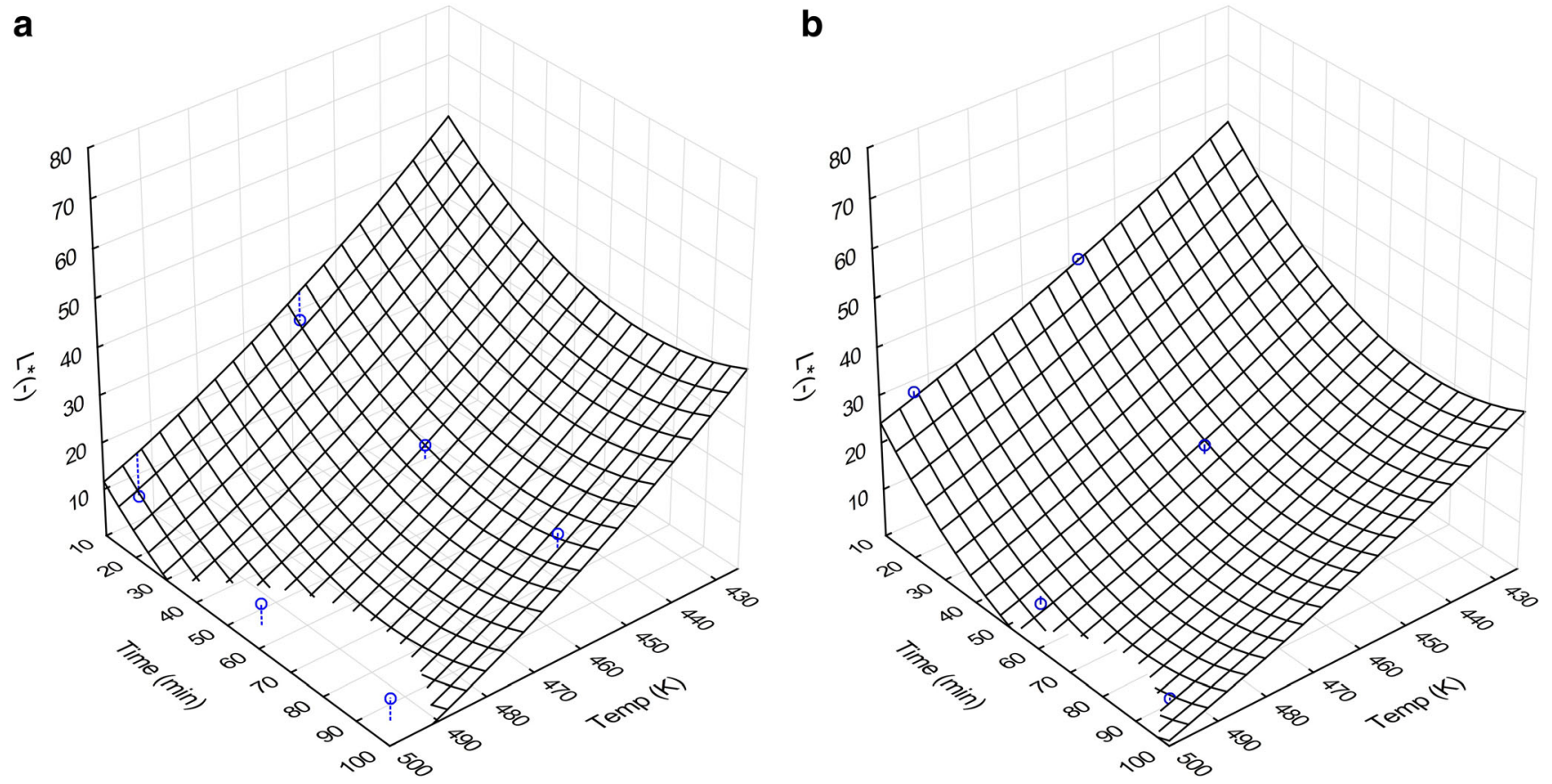

Fig. 5 Color parameter value L* of milled roasted kilned malt (a) and green malt (b) with respect to process parameters

role in the expansion of Maillard reaction because water is a major factor during the flavor formation, additionally acting as a solvent and thereby affecting the mobility of the basic compounds taking part in chemical reactions. Therefore, the roasting of green malt follows a different course of Maillard reaction assisted by water as a solvent as compared to the dry malt, wherein malt roasting at a lower moisture content is dominated by non-enzymatic browning reactions in
Table 9 Chromatographic conditions

\begin{tabular}{|c|c|c|c|c|}
\hline \multicolumn{5}{|l|}{ Chromatographic conditions } \\
\hline \multirow[t]{5}{*}{ HPLC system } & \multicolumn{4}{|c|}{ Series 1200/1260 HPLC (Agilent Technologies) } \\
\hline & \multicolumn{4}{|c|}{ Degasser (G1322A) } \\
\hline & \multicolumn{4}{|c|}{ Binary pump (G1312B) } \\
\hline & \multicolumn{4}{|c|}{ High-performance autosampler (G1367E) } \\
\hline & \multicolumn{4}{|c|}{ Thermostatted column compartment (G1316A) } \\
\hline Pre-column & \multicolumn{4}{|c|}{$\begin{array}{l}\text { Agilent } 1290 \text { infinity in-line filter (PN: 5067-4368) with } 0.3-\mu \mathrm{m} \text { frit ring installed } \\
\text { (PN: 5023-0271) }\end{array}$} \\
\hline Column & \multicolumn{4}{|c|}{ HILIC Plus RRHD (Agilent), $100 \mathrm{~mm} \times 2.1 \mathrm{~mm}$ i.d., $1.8-\mu \mathrm{m}$ particle size } \\
\hline Column oven temperature & \multicolumn{4}{|c|}{$45^{\circ} \mathrm{C}$} \\
\hline Injection volume & \multicolumn{4}{|l|}{$2 \mu \mathrm{L}$} \\
\hline Mobile phase & $\begin{array}{l}\text { Eluent } \\
\text { Eluent }\end{array}$ & \multicolumn{2}{|c|}{ Eluent A: $\mathrm{H} 2 \mathrm{O} \mathrm{w} / 20 \mathrm{mM}$ ammonium formate $+0.2 \%$ formic acid } & acid \\
\hline \multirow[t]{8}{*}{ Gradient } & $\begin{array}{l}\text { Time } \\
{[\mathrm{min}]}\end{array}$ & $\%$ eluent $\mathrm{A}$ & $\%$ eluent B & $\begin{array}{l}\text { Flow } \\
{[\mathrm{mL} / \mathrm{min}]}\end{array}$ \\
\hline & 0 & 3 & 97 & 0.3 \\
\hline & 0.3 & 3 & 97 & 0.3 \\
\hline & 4 & 30 & 70 & 0.3 \\
\hline & 5 & 60 & 40 & 0.3 \\
\hline & 7 & 60 & 40 & 0.3 \\
\hline & 7.10 & 3 & 97 & 0.3 \\
\hline & 15 & 3 & 97 & 0.3 \\
\hline Total analysis time & \multicolumn{4}{|c|}{$15 \mathrm{~min}$, post time $3 \mathrm{~min}$} \\
\hline
\end{tabular}


Table 10 Mass spectrometry conditions

\begin{tabular}{|c|c|c|c|c|c|}
\hline \multicolumn{6}{|c|}{ Mass Spectrometry Conditions } \\
\hline MS system & \multicolumn{5}{|c|}{ Agilent Technologies 6460A Triple Quad LC/MS } \\
\hline Ionisation type & \multicolumn{5}{|c|}{ Electrospray (ESI, Agilent Jet Stream, G1958-65138) } \\
\hline Polarity & \multicolumn{5}{|c|}{ Positive ion mode } \\
\hline $\begin{array}{l}\text { Drying Gas } \\
\text { Temperature }\end{array}$ & \multicolumn{5}{|l|}{$325^{\circ} \mathrm{C}$} \\
\hline Drying gas flow & \multicolumn{5}{|c|}{$9(1 / \mathrm{min})$} \\
\hline $\begin{array}{l}\text { Sheath Gas } \\
\text { Heater }\end{array}$ & \multicolumn{5}{|c|}{$350^{\circ} \mathrm{C}$} \\
\hline $\begin{array}{l}\text { Sheath Gas } \\
\text { Flow }\end{array}$ & \multicolumn{5}{|c|}{$11(1 / \mathrm{min})$} \\
\hline $\begin{array}{l}\text { Nebulizer } \\
\text { pressure }\end{array}$ & \multicolumn{5}{|l|}{40 (psi) } \\
\hline $\begin{array}{l}\text { Capillary } \\
\text { voltage }\end{array}$ & \multicolumn{5}{|c|}{$2500(\mathrm{~V})$} \\
\hline Nozzle voltage & \multicolumn{5}{|c|}{$0(\mathrm{~V})$} \\
\hline Scan type & \multicolumn{5}{|c|}{ MS/MS, Multiple Reaction Monitoring (MRM) } \\
\hline \multirow[t]{4}{*}{ Time segments } & Index & $\begin{array}{l}\text { Start Time } \\
(\mathrm{min})\end{array}$ & Divert Val & $\mathrm{De}$ & ta EMV \\
\hline & 1 & 0 & To Wast & & 0 \\
\hline & 2 & 5.6 & To MS & & 0 \\
\hline & 3 & 7.8 & To Wast & & 0 \\
\hline Scan resolution & \multicolumn{5}{|c|}{ MS1- Wide $(1.2 \mathrm{amu}) / \mathrm{MS} 2-$ Unit $(0.7 \mathrm{amu})$} \\
\hline $\begin{array}{l}\text { Analyte } \\
\text { monitored }\end{array}$ & Ion 1 & $\begin{array}{l}\text { transition } \\
\text { iitored } \\
\mathrm{n} / \mathrm{z})\end{array}$ & $\begin{array}{l}\text { Fragmentor } \\
\text { (V) }\end{array}$ & $\begin{array}{l}\text { Collision } \\
\text { energy } \\
\text { (V) }\end{array}$ & $\begin{array}{c}\text { Cell } \\
\text { Accelerat } \\
\text { orVoltag } \\
\mathrm{e}\end{array}$ \\
\hline \multirow{2}{*}{ Mepiquat } & & $\rightarrow 98.2$ & 106 & 28 & 4 \\
\hline & & $\rightarrow 58.2$ & 106 & 28 & 4 \\
\hline \multirow{2}{*}{ Chlormequat } & & $\rightarrow 63.1$ & 116 & 20 & 4 \\
\hline & & $\rightarrow 58.1$ & 116 & 32 & 4 \\
\hline \multirow{2}{*}{$\begin{array}{c}\text { ISTD } \\
\text { Chlormequat- } \\
\text { D4 }\end{array}$} & & $\rightarrow 58.2$ & 108 & 20 & 4 \\
\hline & \multicolumn{2}{|c|}{$126.1 \rightarrow 67.1$} & 108 & 36 & 4 \\
\hline \multirow{2}{*}{$\begin{array}{l}\text { ISTD Mepiquat- } \\
\text { D3 }\end{array}$} & \multirow{2}{*}{\multicolumn{2}{|c|}{$\begin{array}{c}117.1 \rightarrow 101.2 \\
117.1 \rightarrow 61.2\end{array}$}} & 112 & 28 & 4 \\
\hline & & & 112 & 28 & 4 \\
\hline
\end{tabular}

combination to the phenomenon of pyrolysis. The direct decarboxylation without the role of Maillard-like reaction can also be postulated for the formation of MPQ and CHLM in the case of kilned malt.

Quantitative results of the amount of MPQ, CHLM formed, and observed $\mathrm{L}^{*}$ values are presented in Tables 1 and 2. The first order polynomial model was used for two- factor design. The coded and real value of the independent variables with design matrix is presented in Tables 1 and 2 . The values below the minimum limit of quantification/method sensitivity $(0.005 \mathrm{mg} / \mathrm{kg})$ are presented as zero. Results of variance analysis of an empirical model for MPQ and CHLM content in green and dried malt are shown in Tables 3 and 4 and Tables 5 and 6 respectively. Results of 
variance analysis of ground malt color parameter $(* \mathrm{~L})$ in green and dried malt are shown in Tables 7 and 8 respectively.

From Figs. 3a and 4a, it can be seen that the MPQ content increases with increase in temperature from 0 to $0.5 \mathrm{mg} / \mathrm{kg}$. Effect of roasting time is visible at higher process temperatures while there is a very less or even negligible effect of roasting at lower temperatures. The effects of process variables on the CHLM content of roasted malt are presented in Fig. 4b; CHLM was found to be present at lower roasting temperature. Process temperature was the most important factor that affected the CHLM formation, but at higher temperatures, the treatment time starts to be the significant factor. This indicates that the formation of CHLM and MPQ is dependent on the heat supply, not temperature only. As shown in Fig. 5a, $\mathrm{b}, \mathrm{L}^{*}$ values of milled malt quickly decrease with the increase of process temperature and process time. Higher roasting temperature above $480 \mathrm{~K}$ is able to produce the deep dark malt. In the process of roasting dry malt, the CHLM presence was detected at a temperature above $160{ }^{\circ} \mathrm{C}$, while the MPQ content was measurable at a temperature above $170{ }^{\circ} \mathrm{C}$. The roasting of green malt caused an increase in the process temperature at which CHLM and MPQ content was detected (Tables 9 and 10).

\section{Conclusion}

This study reports the formation of CHLM and MPQ in barley malt roasting process, although the presence and mechanism of MPQ formation are already reported. It is the first report where CHLM has been identified to be formed during the roasting process. The investigations on the mechanism of CHLM formation are not targeted in this study. The hypothesized mechanism could be Maillard-like reaction or direct decarboxylation reaction similar to MPQ formation. The partial support for this hypothesis arises from structure similarity of trigonelline, choline, betaine, and CHLM and MPQ. This mechanism of CHLM formation certainly needs more investigation to prove the hypothesis. The key factor, which determined the amount of compounds produced in the course of roasting, is temperature; duration of roasting is of lesser effect. A reduction of the duration of roasting at low temperatures may result in incomplete browning of malt grains. It was found that CHLM is a compound, which is synthesized at lower temperatures with a shorter roasting time. In the process of roasting dry malt, the CHLM presence was detected at a temperature above $433 \mathrm{~K}\left(160^{\circ} \mathrm{C}\right)$, while the MPQ content was measurable only at a temperature above $442 \mathrm{~K}\left(169^{\circ} \mathrm{C}\right)$. Roasting of green malt caused an increase in the process temperature at which CHLM and MPQ content was detected. In the case of roasting green malt, the CHLM content was detected above the roasting temperature of $435 \mathrm{~K}\left(162{ }^{\circ} \mathrm{C}\right)$ and roasting time of $30 \mathrm{~min}$. The MPQ content increased above the detection level in the course of treatment at a temperature of $450 \mathrm{~K}\left(177^{\circ} \mathrm{C}\right)$.

Open Access This article is distributed under the terms of the Creative Commons Attribution 4.0 International License (http:// creativecommons.org/licenses/by/4.0/), which permits unrestricted use, distribution, and reproduction in any medium, provided you give appropriate credit to the original author(s) and the source, provide a link to the Creative Commons license, and indicate if changes were made.

\section{References}

Bekedam, E. K., Loots, M. J., Schols, H. A., Van Boekel, M. A. J. S., \& Smit, G. (2008). Roasting effects on formation mechanisms of coffee brew melanoidins. Journal of Agricultural and Food Chemistry, 56(16), 7138-7145. https://doi.org/10.1021/jf800999a.

Bessaire, T., Tarres, A., Stadler, R. H., Wermann, S., Hofmann, J., Theurillat, V., Combremont, R., \& Delatour, T. (2016). Mepiquat: a process-induced byproduct in roasted cereal-based foodstuffs. Journal of Agricultural and Food Chemistry, 64(5), 1185-1190. https://doi.org/10.1021/acs.jafc.5b05418.

Bonvallot, N., Canlet, C., Tremblay-Franco, M., Blas-Y-Estrada, F., Gautier, R., Cordier, S., \& Cravedi, J.-P. (2014). A low-dose of a complex pesticide mixture disrupts the metabolome of pregnant rats and their offspring. Toxicol. Lett. Supplement, S234, S234. https:// doi.org/10.1016/j.toxlet.2014.06.782.

Corol, D.-I., Ravel, C., Raksegi, M., Bedo, Z., Charmet, G., Beale, M. H., Shewry, P. R., \& Ward, J. L. (2012). Effects of genotype and environment on the contents of betaine, choline, and trigonelline in cereal grains. Journal of Agricultural and Food Chemistry, 60(21), 5471-5481. https://doi.org/10.1021/jf3008794.

EFSA. 2008. Conclusion regarding the peer review of the pesticide risk assessment of the active substance mepiquat. EFSA Scientific Report, 146 1-73.

Gruber, M.A., 2001. The flavor contributions of kilned and roasted products to finished beer styles. Tech. Q. Master Brew. Assoc. Am., 38, 227-233

Hammel, Y.-A., Dubois, M., Delatour, T., \& Stadler, R. H. (2014). N,Ndimethylpiperidinium (mepiquat): part 1. Formation in model systems and relevance to roasted food products. Food Addit. Contam. Part A, 31(2), 226-233. https://doi.org/10.1080/19440049.2013. 871584.

Jones, O. A. H., Murfitt, S., Svendsen, C., Turk, A., Turk, H., Spurgeon, D. J., Walker, L. A., Shore, R. F., Long, S. M., \& Griffin, J. L. (2013). Comparisons of metabolic and physiological changes in rats following short term oral dosing with pesticides commonly found in food. Food and Chemical Toxicology, 59, 438-445. https://doi.org/ 10.1016/j.fct.2013.06.041.

Kim, K., Kim, M., Kang, Y., \& Lee, Y. (1993). Effects of malting conditions on quality characteristics of malt and roasted malt extract. Cereal Chemistry, 70, 440-442.

Lee, S.-M., Lee, K.-T., Lee, S.-H., \& Song, J.-K. (2013). Origin of human colour preference for food. Journal of Food Engineering, 119(3), 508-515. https://doi.org/10.1016/j.jfoodeng.2013.06.021.

Mizukami, Y., Yoshida, M., Isagawa, S., Yamazaki, K., \& Ono, H. (2014). Acrylamide in roasted barley grains: presence, correlation with colour and decrease during storage. Food Addit. Contam Part A, 31(6), 995-1000. https://doi.org/10.1080/19440049.2014. 910614.

Mizukami, Y., Yoshida, M., \& Ono, H. (2016). Acrylamide elution from roasted barley grains into mugicha and its formation during roasting. 
Food Addit. Contam. Part Chem. Anal. Control Expo. Risk Assess., 33, 225-235. https://doi.org/10.1080/19440049.2015.1128567.

Moreira, A. S. P., Nunes, F. M., Domingues, M. R., \& Coimbra, M. A. (2012). Coffee melanoidins: structures, mechanisms of formation and potential health impacts. Food \& Function, 3(9), 903-915. https://doi.org/10.1039/c2fo30048f.

Nisse, P., Majchrzak, R., Kahn, J. P., Mielcarek, P., \& Mathieu-Nolf, M. (2015). Chlormequat poisoning is not without risk: examination of seven fatal cases. Journal of Forensic and Legal Medicine, 36, 1-3.

Ohta, N., Robertson, A.R., 2005. Uniform color spaces, in: Colorimetry. John Wiley \& Sons, Ltd, pp. 115-151. doi:https://doi.org/10.1002/ 0470094745.ch4

Papetti, A., Daglia, M., Aceti, C., Quaglia, M., Gregotti, C., \& Gazzani, G. (2006). Isolation of an in vitro and ex vivo antiradical melanoidin from roasted barley. Journal of Agricultural and Food Chemistry, 54(4), 1209-1216. https://doi.org/10.1021/jf058133x.

Torner, H., Blottner, S., Kuhla, S., Langhammer, M., Alm, H., \& Tuchscherer, A. (1999). Influence of chlorocholinechloride-treated wheat on selected in vitro fertility parameters in male mice. Reprod. Toxicol Elmsford N, 13(5), 399-404.

Wang, H.-Y., Qian, H., \& Yao, W.-R. (2011). Melanoidins produced by the Maillard reaction: structure and biological activity. Food
Chemistry, 128(3), 573-584. https://doi.org/10.1016/j.foodchem. 2011.03.075.

Wermann, S., Theurillat, V., Verzegnassi, L., Hofmann, J., Kuchenbecker, R., Constable, A., Delatour, T., \& Stadler, R. H. (2014). N, Ndimethylpiperidinium (mepiquat) part 2. Formation in roasted coffee and barley during thermal processing. Food Addit. Contam Part A, 31(2), 234-241.

Xiagedeer, B., Wu, S., Liu, Y., \& Hao, W. (2016). Chlormequat chloride retards rat embryo growth in vitro. Toxicol. Vitro Int. J. Publ. Assoc. BIBRA, 34, 274-282. https://doi.org/10.1016/j.tiv.2016.05.001.

Yuan, Y., Tarres, A., Bessaire, T., Rademacher, W., Stadler, R. H., \& Delatour, T. (2017a). Heat-induced formation of mepiquat by decarboxylation of pipecolic acid and its betaine derivative. Part 2: natural formation in cooked vegetables and selected food products. Food Chemistry, 228, 99-105. https://doi.org/10.1016/j.foodchem.2017. 01.122 .

Yuan, Y., Tarres, A., Bessaire, T., Stadler, R. H., \& Delatour, T. (2017b). Heat-induced formation of mepiquat by decarboxylation of pipecolic acid and its betaine derivative. Part 1: model system studies. Food Chemistry, 227, 173-178. https://doi.org/10.1016/j. foodchem.2017.01.095. 